\title{
Antioxidant Enrichment of Baobab Fruit Pulp Treated with Oil Extracted from the Seeds
}

\author{
Addai-Mensah Donkor ${ }^{1 *}$, Daniel Addae ${ }^{2}$, Jemima Esi Kpoanu ${ }^{2}$, Frank Kankam², \\ Abraham Nwolley Boaudi ${ }^{2}$, Evans Yaw Manu Abanya ${ }^{2}$ \\ ${ }^{1}$ Department of Applied Chemistry and Biochemistry, Faculty of Applied Sciences, University for Development Studies, Na- \\ vrongo, Ghana; ${ }^{2}$ Department of Applied Biology, Faculty of Applied Sciences, University for Development Studies, Navrongo, \\ Ghana. \\ Email: *
}

Received October $31^{\text {st }}, 2013$; revised November $30^{\text {th }}, 2013$; accepted December $7^{\text {th }}, 2013$

Copyright (C) 2014 Addai-Mensah Donkor et al. This is an open access article distributed under the Creative Commons Attribution License, which permits unrestricted use, distribution, and reproduction in any medium, provided the original work is properly cited. In accordance of the Creative Commons Attribution License all Copyrights (C) 2014 are reserved for SCIRP and the owner of the intellectual property Addai-Mensah Donkor et al. All Copyright (C) 2014 are guarded by law and by SCIRP as a guardian.

\section{ABSTRACT}

The effect of the application of oil from baobab seeds on the antioxidant capacity and stability of ascorbic acid in the fruit pulp at varying temperature were evaluated. Ascorbic acid analysis of the fruit pulp revealed that the concentration in the raw extract of the pulp sullied rapidly matched with the extract treated with the seed oil. Compared with the raw extracts the formulated fruit pulp presented the highest concentration of the total ascorbic acid when both samples were subjected to varying temperatures at extended time periods. The results clearly indicated the antioxidant enrichment property of the baobab seed oil. This study demonstrates the potential of oil derived from baobab seed as having antioxidant enrichment capacity and might be a potential ingredient in pharmaceutical cosmetics formulations and food preparations.

\section{KEYWORDS}

Baobab; Seed Oil; Antioxidant Capacity; Enrichment

\section{Introduction}

Baobab (Adansonia digitata) fruit pulp has been used as food ingredients in a variety of food formulations and could also be eaten raw. It is known to contain high levels of vitamins, nutrients, micro nutrients and antioxidants. Baobab fruit pulp is rich in ascorbic acid, calcium, tartaric acid and potassium bitartrate [1] and its usage in food fermentation is a common practice in Africa. The pulp is traditionally consumed in Africa by children, expectant mothers and senior citizens due to the high content of vitamins and nutrients which help fight off illnesses and provide excellent source of nourishment. In traditional medicine baobab fruit pulp is used in the treatment of fevers, diarrhea and malaria. Due to ample natural vitamin C content, baobab fruit pulp has a well-documented antioxidant capability [2]. It is in this background that baobab fruit pulp is used as milk substitute for babies in

${ }^{*}$ Corresponding author. some African countries [3]. In addition to the fact that vitamin $\mathrm{C}$ supports the absorption of iron and calcium into the body the fruit pulp is known to have been consumed in order to avoid scurvy [4].

Antioxidants have the potential of preventing oxidative stress related diseases such as cancer, aging, inflammation and cardio-vascular diseases as they eradicate free radicals which contribute to these chronic diseases $[5,6]$. It is established that a diet rich in fruit and vegetables, which include an abundance of antioxidants such as vitamin $\mathrm{C}$ and $\mathrm{E}$ as well as phenolic compounds and carotenoids, can aid in preventing oxidative related ailments [6]. The antioxidant capacity of the baobab fruit pulp was studied by means of photochemiluminescence assay [7]. Evaluation of antioxidant properties of the fruit pulp to the antioxidant properties of numerous other fruits comprising kiwi, orange, apple and strawberry showed that the baobab fruit has the maximum content of 
vitamin C at 150 - $499 \mathrm{mg} / 100 \mathrm{~g}$, out of all fruits investigated. This compared to a vitamin C content of 53 $\mathrm{mg} / 100 \mathrm{~g}$ in oranges as well as documented sources of vitamin C. Baobab fruit pulp was found to have the highest water-soluble $(6.96 \mathrm{mmol} / \mathrm{g})$, lipid-soluble (4.148 $\mathrm{mmol} / \mathrm{g}$ ) and, therefore, total antioxidant capacities of all the fruits investigated. The authors of the study upon examination of the results suggested that because of the level of the antioxidant capacity, baobab fruit is a new valuable ingredient for food preparation and/or nutraceutical application in the promotion of health [7]. The high vitamin $\mathrm{C}$ content of the fruit pulp may have a role in the extension of shelf-life for foods and beverages, as well as cosmetics.

The baobab seed is attached to fibrous strands from the wall of the fruit and are embedded in a yellowish-white pulp. They are arranged in rows in two to eight locales per fruit. Baobab seed is a good source of energy, protein and fat. The seeds are mostly used as a thickener for soups, but may also be fermented into a seasoning, roasted for direct consumption, or pulverized to extract vegetable oil $[8,9]$.

Most vegetable oils found in the market are known to be highly saturated posing health related complications. In view of the shortfall in vegetable oils, studies on seeds of lesser known species have received attention in recent times of which baobab is no exception. The oil from the baobab seed contains about 1 - $2 \mathrm{mg} / \mathrm{g}$ linoleic acid which is an essential fatty acid required by the body for growth and development. The high content of mono and poly unsaturated fatty acids suggests that the baobab seed oil consumed may help lower cholesterol level [10]. These properties make the baobab seed oil a good option for preparing healthier foods and as both additive and preservative.

In this study, the aim was to show the fortification of ascorbic acid content and the increment of the antioxidant capacity of baobab fruit pulp with oil extracted from the seeds.

\section{Materials and Methods}

\subsection{Materials}

Commercial pure L-ascorbic acid, 100 grams, $0.5 \mathrm{~g}$ quantity of 2, 6-dichlorophenolindophenol (DCPIP), and $12.5 \mathrm{~cm}$ size of Fluted Filter Paper were purchased from Benburto Chemical Enterprises Ltd, Accra, Ghana. Baobab fruit was harvested from Navrongo in the Upper East Region of Ghana. Fruits were cracked and the seed kernels were manually removed from the seed shell using a knife. Sonicator, UV-Vis Spectrophotometer, centrifuge, and Sohxlet extractor were obtained from the laboratory of the Department of Applied Chemistry \& Biochemistry, University for Development Studies.

\subsection{Preparation of Raw Extract of Baobab Fruit Pulp}

The fruit was ruptured into two halves and the pulp scrapped out with a plastic spoon. The semi-powdered pulp sample, $10 \mathrm{~g}$ was weighed, pulverized and dispersed in $250 \mathrm{ml}$ of deionized water using a porcelain pestle and mortar. The mixture was then sonicated, centrifuged and the supernatant filtered through rapid fluted filter paper.

\subsection{Extraction of Seed Oil}

The seed kernels were pulverized into fine powder using mortar and pestle and the powdered seed kernel, $40 \mathrm{~g}$, was used for the extraction process using a Sohxlet extractor. Organic solvents hexane and petroleum ether, $200 \mathrm{ml}$ each was measured into separate $250 \mathrm{ml}$ round bottom and the Sohxlet with a thimble containing the seed powder and a condenser were assembled. The solvent mixture of both the hexane and the petroleum ether fractions were separately refluxed for 4 hours. Each of the mixture was concentrated using rotary evaporator to obtain light yellowish oil, yield of $11.48 \mathrm{~g}$ and $5.24 \mathrm{~g}$ for oil extract from petroleum ether and hexane respectively.

\subsection{Formulation of Baobab Fruit Pulp with the Seed Oil}

Baobab seed oil, $2 \mathrm{ml}$ was added to $10 \mathrm{~g} / 100 \mathrm{ml}$ of baobab fruit pulp in a flask. The content was sonicated continuously at room temperature for one hour, centrifuged and the supernatant was decanted. The mixture was further filtered through sterile cotton wool and the filtrate was kept at $10^{\circ} \mathrm{C}$ for the next experiment. The process was repeated at an hour interval up to three hours and the filtrate were collected. The formulation process continued with samples heated at various temperatures ranging from $25,40,60$ and $80^{\circ} \mathrm{C}$ respectively.

\subsection{Determination of Ascorbic Acid Content}

Standard method using DCPIP was used to determine the ascorbic acid content [11]. Experiments' were performed in triplicates to confirm reproducibility.

\section{Physico-Chemical Characterization of Baobab Seed Oil}

\subsection{Iodine Value Determination}

Extracted baobab oil, $1 \mathrm{ml}$ was poured into a clean conical flask and titrated with $0.1 \mathrm{M}$ iodine solution. Near the endpoint (marked by the appearance of a light yellow colour), about 2 drops of starch indicator was added. The titration continued until the end point was reached (where there was a colour change from deep blue to colourless) and the titer value was recorded. This was re- 
peated three more times to validate the consistency of the titer values.

\subsection{Peroxide Number Determination}

Extracted baobab oil, $1.0 \mathrm{~g}$ was measured into a clean conical flask. $20 \mathrm{ml}$ ethanoic acid and $15 \mathrm{ml}$ chloroform were added. Potassium iodide reagent, $10 \mathrm{ml}$ was again added to the mixture and stirred carefully. The mixture was allowed to stand for two minutes and $15 \mathrm{ml}$ of distilled water was finally added to the resulting solution. The solution was then titrated against $0.1 \mathrm{M} \mathrm{Na}_{2} \mathrm{~S}_{2} \mathrm{O}_{3}$. Near the end point about $5 \mathrm{ml}$ of freshly prepared starch solution was added, and slowly titrated to the endpoint.

\subsection{Determination of Partition Coefficient of Baobab Seed Oil}

Extracted oil, $5.0 \mathrm{ml}$ each was emptied into $100 \mathrm{ml}$ sterile tubes containing $25 \mathrm{ml}$ each of octanol and buffer solutions respectively. The tubes were inserted into an equilibrium mixer apparatus and were allowed to rotate and mix thoroughly for 48 hours. The mixture was allowed to stand for phase separation. The two phases, octanol and aqueous layers were separated. The absorbance of the oil in each solution was measured at $340 \mathrm{~nm}$ using UV-Vis spectro photometer. The corresponding concentrations of the samples in each solution were then extrapolated from established standard curves.

\subsection{Statistical Analysis}

The data for the reduction in mass at varying temperature of ascorbic acid content in both the raw and formulated baobab fruit pulp were statistically scrutinize dusing the one-way ANOVA to determine if they were significantly different at $P<0.05$.

\section{Results}

For each $60 \mathrm{~g}$ of seeds processed in $400 \mathrm{ml}$ of petroleum ether, the yield of the oil was approximately $8.37 \mathrm{~g}$. Applying standard curves the concentrations of oil in octanol and that of ascorbic acid in the raw and formulated fruit pulp samples were extrapolated from the graphs (Figures 1 and 2). Initial ascorbic content in the formulated fruit pulp was significantly higher than the raw pulp. The ascorbic acid content in both the raw pulp extract and the formulated samples were found to degrade with increase in temperature. Comparing the rate at which ascorbic acid in the formulated and that of the raw baobab extracts, the raw extracts denigrated faster when temperature was increased at longer period of time.

Increasing temperature from $25^{\circ} \mathrm{C}$ to $40^{\circ} \mathrm{C}$ did not have any significant difference. On the mass of ascorbic acid content in both the raw fruit and the formulated pulp

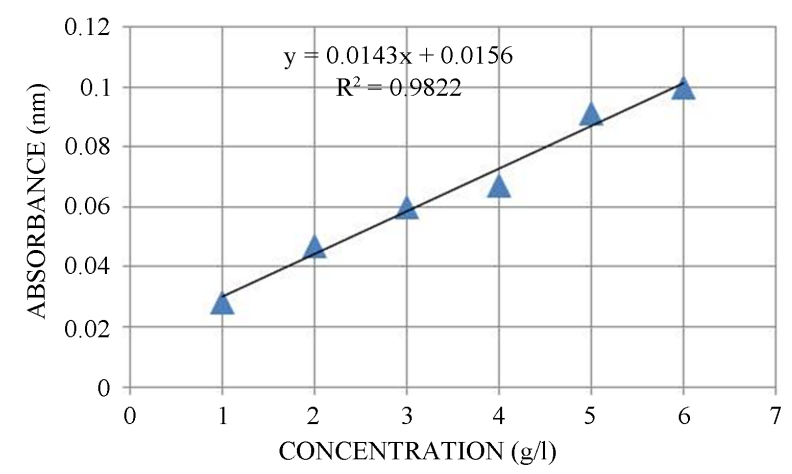

Figure 1. Standard curve of absorbance versus concentration of oil in octanol.

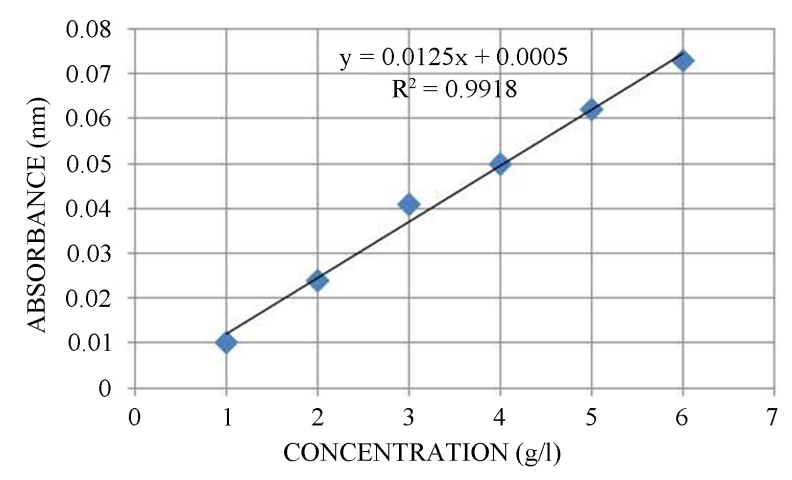

Figure 2. Standard curve of absorbance against concentration for pure ascorbic acid.

during the initial one hour storage period (Figure 3). However, when temperature was raised between $\left(40^{\circ} \mathrm{C}\right.$ $\left.80^{\circ} \mathrm{C}\right)$, there was significant difference $(P<0.05)$, in the reduction of ascorbic acid content in both samples compared with standard ascorbic acid. The reduction was pronounced at the storage time of two hours, for both the raw pulp and the pulp treated with the seed oil (Figure 4).

The iodine value was determined to estimate the amount of unsaturation present in the baobab seed oil. Since unsaturated fatty acids are "softer" or less firm, iodine value could be used as indicator of overall oil firmness. A limited amount of research has indicated that the maximum acceptable iodine value should be 70 g per $100 \mathrm{~g}$ [12,13] or $75 \mathrm{~g}$ per $100 \mathrm{~g}$ [14]. Employing simple titration method, the iodine value of the baobab seed oil was found to be $65.22 \mathrm{~g} / 100 \mathrm{~g}$.

Oils are susceptible to rancidity because of their chemistry which makes them vulnerable to oxygen damage. Rancid fats have been associated with increased rates of heart disease, atherosclerosis and are carcinogenic. The oxidation resulting from the exposure of oil to atmospheric air is the principal basis for rancidity, the more polyunsaturated a fat is, the higher tendency it becomes susceptible to rancidity. The peroxide value of oil measures the extent to which rancidity reactions have oc- 


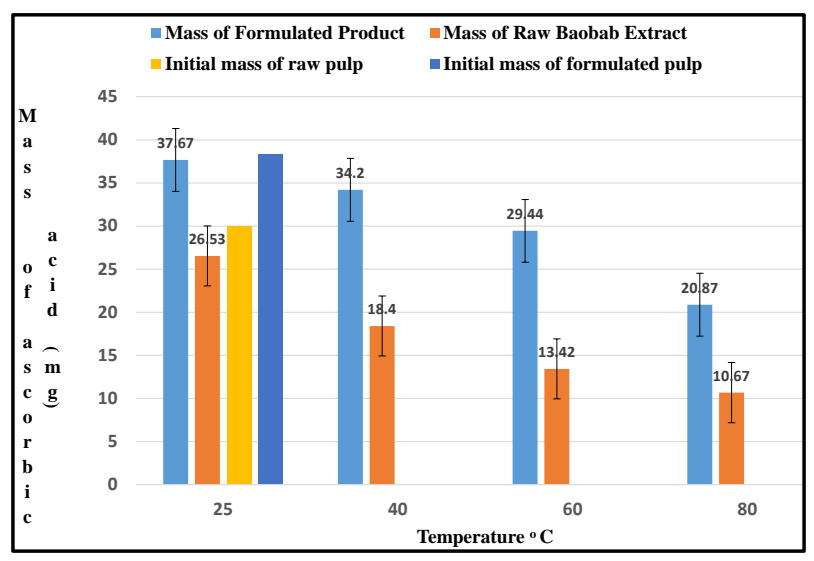

Figure 3. Graph showing ascorbic acid content in both formulated and raw baobab extract stored for 1 hour at temperature ranging between $25^{\circ} \mathrm{C}$ and $80^{\circ} \mathrm{C}$.

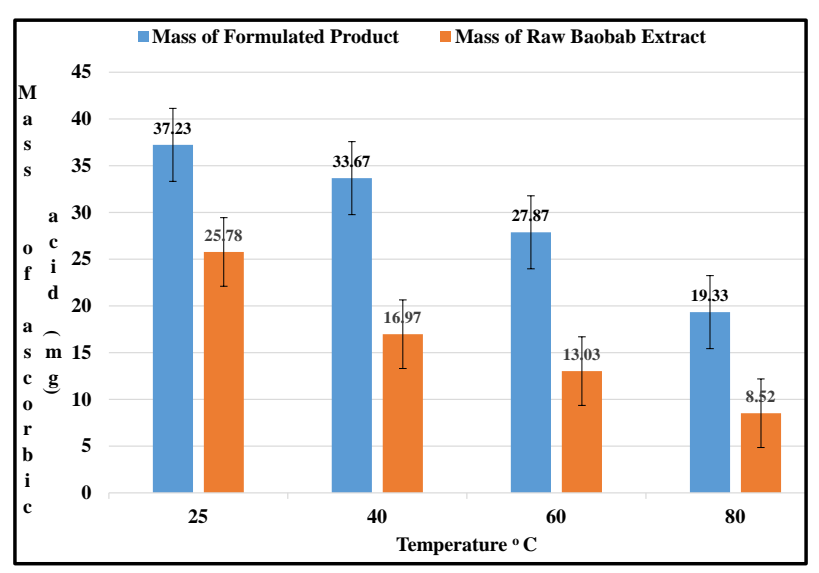

Figure 4. Graph showing ascorbic acid content in both formulated and raw baobab extract stored for 2 hour at temperature ranging between $25^{\circ} \mathrm{C}$ and $80^{\circ} \mathrm{C}$.

curred during storage. Oils with a high degree of unsaturation are most susceptible to autoxidation and peroxide value, as far as research is concerned is the best test for autoxidation rancidity. Here redox titration in nonaqueous media was employed, and results expressed in mmol of peroxide (or active oxygen) per kilo gram of product. In general, the lower the peroxide value, the better the quality of the oil. However peroxide value decreases as secondary oxidation products appear [15]. It has been established that peroxide value is less than 10 in marine oils, but it may need to be as low as 2, depending on the market. The peroxide value for the baobab seed oil was determined to be $4.001 \mathrm{mmol} / \mathrm{kg}$ of the baobab seed oil from Ghana.

Determination of pKa and $\log P$ are essential in understanding the behavior of drug molecules or compounds.
Partition coefficient in combination with pKa is employed to predict the distribution of a drug compound in a biological system. We therefore extrapolated drug distribution concept in this present research to validate where the baobab seed oil may be mostly distributed in the biological system. In determining the above parameters, the concentration of the baobab seed oil in both octanol and buffer solutions respectively were extrapolated from standard curves and the apparent partition coefficients (Table 1) were evaluated using the expression in Equation (1) below.

The true partition coefficient was determined applying Equation (2) below, by plotting a graph of the reciprocal of apparent partition coefficient $1 / P_{a p p}$ against the reciprocal of hydrogen ion concentrations, $1 /\left[\mathrm{H}^{+}\right]$(Figure 5).

$$
\frac{1}{P_{a p p}}=\frac{1}{P}+\left(\frac{\mathrm{Ka}}{P}\right) \times \frac{1}{\left[\mathrm{H}^{+}\right]}
$$

where, $P_{a p p}=$ apparent partition coefficients of oil samples (Table 2).

$P$ is the true partition coefficient of the oil sample which was deduced from the intercept of the graph (Figure 5): $\left[\mathrm{H}^{+}\right]=$Hydrogen ion concentration in each of the buffer solutions The slope of the graph gave $\mathrm{Ka} / P$, from which the pKa was determined.

\section{Discussion}

Analyses were made on the raw baobab fruit pulp extract and the extract formulated with the seed oil at varying temperatures ranging from $25^{\circ} \mathrm{C}$ to $80^{\circ} \mathrm{C}$. It was observed that ascorbic acid content in both samples degraded with increase in temperature and time. Comparing the rate at which ascorbic acid content in both the formulation and the raw pulp extract degraded, it was observed that ascorbic acid in the raw extract degraded rapidly at higher temperatures and at longer time of exposure of three hour storage (Figure 6). The baobab seed oil applied to the fruit pulp positively influenced the stability of the ascorbic acid content in the fruit pulp. Not only did the seed oil enrich the ascorbic acid content at varying temperature but also gave an indication of some level of ascorbic acid content in the seed oil.

The iodine number of fats and oils indicate the level of unsaturation that exists within the molecular structure of that fat or oil. Fats and oils with higher iodine number are easily oxidised by atmospheric oxygen or are easily hydrolysed leading to rancidity of that fat or oil.

The maximum acceptable limits of iodine number ac-

$$
P_{a p p}=\frac{\text { Concentration in organic phase }}{(\text { Concentration of ionized }+ \text { Concentration of unionized }) \text { in buffer solution }}
$$


Table 1. Calculation of apparent partition coefficient after phase separation.

\begin{tabular}{cccc}
\hline $\begin{array}{c}\text { Number of } \\
\text { partitioning } \\
\text { experiments }\end{array}$ & $\begin{array}{c}\text { Concentration } \\
(\mathbf{g} / \mathbf{l}) \text { in buffer } \\
\left(\mathbf{C}_{\mathbf{B}}\right)\end{array}$ & $\begin{array}{c}\text { Concentration } \\
(\mathbf{g} / \mathbf{l}), \begin{array}{c}\text { in octanol } \\
\left(\mathbf{C}_{\mathbf{O}}\right)\end{array}\end{array}$ & $\begin{array}{c}\text { Partition } \\
\text { coefficient } \\
\boldsymbol{P}=\boldsymbol{C}_{\boldsymbol{O}} / \boldsymbol{C}_{\boldsymbol{B}}\end{array}$ \\
\hline P1 & 1.6 & 4 & 2.5 \\
P2 & 2.4 & 4.4 & 1.83 \\
P3 & 5.7 & 5.8 & 1.02 \\
P4 & 5.5 & 6.6 & 1.2 \\
P5 & 3.1 & 3.2 & 1.03 \\
P6 & 4.3 & 6.3 & 1.47 \\
\hline
\end{tabular}

Table 2. Reciprocal of both apparent partition coefficient and that of hydrogen ion concentration.

\begin{tabular}{cccc}
\hline $\mathbf{p H}$ & {$\left[\mathbf{H}^{+}\right]$} & $\frac{1}{\left[\mathrm{H}^{+}\right]}$ & $\frac{1}{P_{\text {app }}}$ \\
\hline 3.0 & 0.001 & 1000 & 0.4 \\
3.4 & 0.000498 & 2511.88 & 0.546 \\
3.8 & 0.000158 & 6309.57 & 0.98 \\
4.2 & 0.000063 & 15848.93 & 0.833 \\
4.6 & 0.000025 & 39810.72 & 0.971 \\
5.0 & 0.00001 & 100000 & 0.68 \\
\hline
\end{tabular}

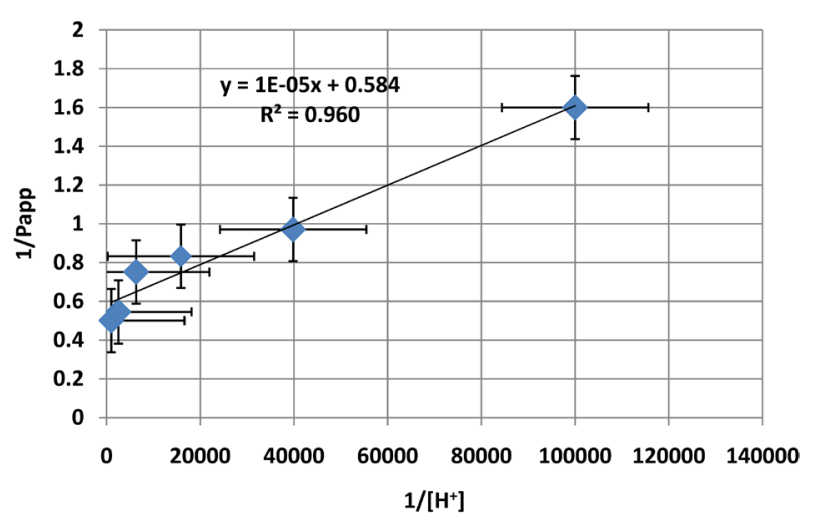

Figure 5. Graph of inverse of apparent partition coefficient $\left(1 / P_{a p p}\right)$ against the inverse of hydrogen ion concentration.

cording to literature reviewed are 70 g per $100 \mathrm{~g}$ and $75 \mathrm{~g}$ per $100 \mathrm{~g}$. Comparing the iodine number of the baobab seed oil (65.25 g per $100 \mathrm{~g}$ ) to the maximum allowable limit, there is a clear indication that the iodine number of the baobab seed oil is very high and close to the maximum allowable limit. This means that the baobab seed oil should have been more susceptible to oxidation and hydrolysis leading to high level of rancidity.

This is actually not seen in the case of the measure of rancidity in the baobab seed oil (peroxide number). The baobab seed oil has high resistance to rancidity even though it has high unsaturation. It has peroxide number of 4.001 which is lower than literature value of 4.05 . This value should have been very high due to high iodine number of the baobab seed oil. Even though the iodine number is high, the peroxide number is relatively low. This may be due to the presence of antioxidant (ascorbic acid) which exists in the baobab seed oil at a very high concentration. This can also accounts for why temperature increase and duration of exposure of the formulation did not have significant decrease on the ascorbic acid content but rather had significant effect on the raw baobab fruit pulp's ascorbic acid concentration. The oil extracted from the seed of the baobab can withstand rancidity, has longer shelf life and can also be used as a preservative due to its high antioxidant property. It also contains high amount of ascorbic acid making it more suitable for human consumption.

Physico-chemical tests conducted on the crude oil extract included $\mathrm{pH}$, peroxide number, iodine value, $\log P$ and $\mathrm{pKa}$. The $\mathrm{pH}$ obtained was between 6.2 - 6.5 revealed that the oil is weakly acidic. The iodine value obtained was 65.22 which is close to research published by [16]. The number of peroxides present in the seed oil is an index of its primary oxidative level and hence its tendency to resist rancidity. The peroxide number of baobab oil obtained in this research was 4.001 . The value obtained is comparable to literature value of 4.05 in the research published by [17].

The $\log P$ and $\mathrm{pKa}$ values of the extracted baobab seed oil were analyzed at $25^{\circ} \mathrm{C}$ using the shake flask and spectrophoto metric methods. The $\log P$ and the pKa values of the seed oil determined from the graph of inverse of apparent partition coefficient against the reciprocal of hydrogen ion concentration (Figure 5) were found to be 2.22 and -3.97 respectively. The $\log P$ value is used to predict whether a compound or a drug would partition well either in the lipid membrane or the plasma. In this research, the $\log P$ determined indicates that, the seed oil extracted is highly lipophilic. Further research about the active components in the oil is currently being investigated in our laboratory.

\section{Conclusion}

The application of extracted oil from baobab seeds increased the total ascorbic acid concentration in the fruit pulp, and enhanced antioxidant enrichment by protecting and stabilizing the ascorbic acid to withstand higher temperatures. It seems reasonable to consider the baobab seed oil and the fruit pulp as essential food sources for diet supplement. In view of the high antioxidant capacity, we propose the seed oil as a new valuable ingredient for food preparation and nutriceutical application in the promotion of health in Ghana. 


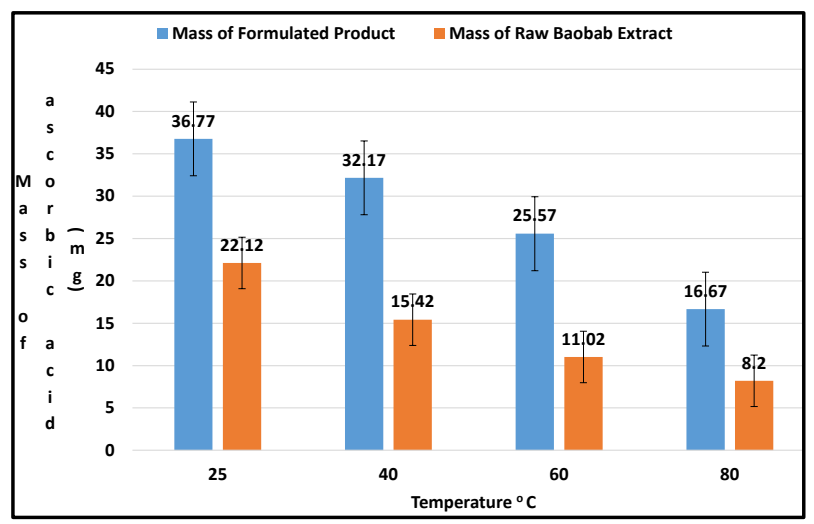

Figure 6. Graph showing ascorbic acid content in both formulated and raw baobab extract stored for 3 hours at temperature ranging between $25^{\circ} \mathrm{C}$ and $80^{\circ} \mathrm{C}$.

\section{Conflict of Interest}

It is hereby declared that the authors have no competing financial interests whatsoever in relation to the work described here. It is purely for academic and intellectual purposes.

\section{Acknowledgements}

All materials and equipment used in this study were provided by the Department of Applied Chemistry and Biochemistry as well as the Microbiology Laboratory of the Department of Applied Biology, both in the Faculty of Applied Sciences of the University for Development Studies, Navrongo.

\section{REFERENCES}

[1] O. R. Afolabi and T. O. S. Popoola, "The Effects of Baobab Pulp Powder on the Micro Flora Involved in Tempe Fermentation,” European Food Research and Technology, Vol. 220, No. 2, 2005, pp. 187-190. http://dx.doi.org/10.1007/s00217-004-0998-y

[2] E. Besco, E. Bracioli, S. Vertuani, P. Ziosi, F. Brazzo, R. Bruni, G. Sacchetti and S. Manfredini, "The Use of Photochemiluminescence for the Measurement of the Integral Antioxidant Capacity of Baobab Products," Food Chemistry, Vol. 102, No. 4, 2007, pp. 1352-1356. http://dx.doi.org/10.1016/j.foodchem.2006.05.067

[3] G. E. Wickens and P. Lowe, "The Baobabs: Pachycauls of Africa, Madagascar and Australia," Springer, Dordrecht, 2008, $498 \mathrm{p}$.

http://dx.doi.org/10.1007/978-1-4020-6431-9

[4] J. Gruenwald and M. Galizia, "Market Brief in the European Union for Selected Natural Ingredients Derived from Native Species, Adansonia digitata L. Baobab,” In The United Nations Conference on Trade and Development (UNCTAD) BioTrade Initiative/BioTrade Facilitation Programme (BTFP) UNCTAD/DITC/TED, 2005.

[5] R. Blomhoff, M. Carlsen, B. Halvorsen, K. Holte, S.
Bohn, S. Dragland, L. Sampson, C. Willey, H. Senoo, Y. Umezono, C. Sanada, I. Barikmo, N. Berhe, W. Willett, K. Phillips and D. Jacobs, "The Total Antioxidant Content of More than 3100 Foods, Beverages, Spices, Herbs and Supplements Used Worldwide,” Nutrition Journal, Vol. 9, No. 1, 2010, p. 3. http://dx.doi.org/10.1186/1475-2891-9-3

[6] C. Kaur and H. C. Kapoor, "Antioxidants in Fruits and Vegetables-The Millenium's Health,” International Journal of Food Science and Technology, Vol. 36, No. 7, 2001, pp. 703-725.

http://dx.doi.org/10.1046/j.1365-2621.2001.00513.x

[7] S. Vertuani, E. Braccioli, V. Buzzoni and S. Manfredini, "Antioxidant Capacity of Adasonia Digitata Fruit Pulp and Leaves," Acta Phytotherapeutic, Vol. 2, 2002, pp. 27.

[8] A. O. Magdi, "Chemical and Nutrient Analysis of Baobab (Adansonia digitata)," Plant Foods for Human Nutrition, Vol. 59, No. 1, 2004, pp. 29-33. http://dx.doi.org/10.1007/s11130-004-0034-1

[9] M. A. Osman, "Chemical and Nutrient Analysis of Baobab Fruit and Seed Protein,” Moisture Food, 2004, p. 29.

[10] I. A. Ajayi, F. A. Dawodi and R. A. Oderinde, "Fatty acid Composition and Metal Content of Adansonia digitata Seeds and Seed Oil," La Rivista Italiana delle Sostanze Grasse, Vol. 80, No. 1, 2003, pp. 41-43.

[11] O. A. Oyetade, G. O. Oyeleke, B. M. Adegoke and A. O. Akintunde, "Stability Studies on Ascorbic Acid (Vitamin C) From Different Sources," IOSR Journal of Applied Chemistry, Vol. 2, No. 4, 2012, pp. 20-24. http://dx.doi.org/10.9790/5736-0242024

[12] P. A. Barton-Gade, "Meat and Fat Quality in Boars, Castrates and Gilts," Livestock Production Science, Vol. 16, No. 2, 1987, pp. 187-196. http://dx.doi.org/10.1016/0301-6226(87)90019-4

[13] A. Madsen, K. Jakobsen and H. Mortensen, "Influence of Dietary Fat on Carcass Fat Quality in Pigs. A Review," Acta Agriculturae Scandinavica, Vol. 42, No. 4, 1992, pp. 220-225. http://dx.doi.org/10.1080/09064709209410132

[14] R. D. Boyd, M. E. Johnston, K. Scheller, A. A. Sosnicki and E. R.Wilson, "Relationship between Dietary Fatty Acid Profileand Body Fat Composition in Growing Pigs," PIC Technical Memo 153, PIC, Franklin, 1997.

[15] B. L. Halvorsen and R. Blomhoff, "Determination of Lipid Oxidation Products in Vegetable Oils and Marine Omega-3 Supplements," Food \& Nutrition Research, Vol. 55, 2011.

[16] U. A. Birnin-Yauri and S. Garba, "Comparative Studies on Some Physicochemical Properties of Baobab, Vegetable, Peanut and Palm Oils," Nigerian Journal of Basic and Applied Science, Vol. 19, No. 1, 2011, pp. 64-67.

[17] I. I. Nkafamiya, S. A. Osemeahon, D. Dahiru and H. A. Umaru, "Studies on the Chemical Composition and Physicochemical Properties of the Seeds of Baobab (Adansonia digitata)," African Journal of Biotechnology, Vol. 6, No. 6, 2007, pp. 756-759. 